\title{
Implementation of a mobile digital tool in the quality area to optimize the process of observation management in residential buildings
}

\author{
A Mesias, Bachelor of School of Civil Engineering ${ }^{1}, \mathrm{R}$ Vasquez, Bachelor of School of Civil Engineering ${ }^{1}$, \\ S Rodriguez, Master of School of Civil Engineering ${ }^{1}$, and H Ramirez, Master of School of Civil Engineering ${ }^{1}$ \\ ${ }^{1}$ Universidad Peruana de Ciencias Aplicadas, Perú, u201411188@upc.edu.pe, u201510532@upc.edu.pe, \\ sandra.rodriguez@upc.edu.pe,pccihram@upc.edu.pe
}

\begin{abstract}
The lack of digitalization has been very evident in the construction sector, one of the affected areas is that of quality, since the filling of forms, the transcription of field information to the computer and the poor communication between project stakeholders generate inefficiency in the process of the observations' management. Those responsible for this activity spend $31 \%$ of their time in monitoring, where $16 \%$ of this time is spent transcribing the information collected in the field. This is relevant at the stage where a greater number of observations are presented, such as the architecture specialty, which represents $60 \%$ of the total observations found in the projects.

With the following premise, this research proposes to redesign the inspection process carried out by the quality area, through the use of a mobile digital tool, generating a better connection with those involved in the project and reducing the time to perform the observations' management so as the waiting time to raise the observations. The redesign of the process includes the use of a mobile digital tool. By applying this proposal, the time involved in the personnel that makes up the project team is reduced, as well as the response time by subcontractors for the observation.
\end{abstract}

Keywords - Construction Management, Digital transformation, Time, Quality control, Mobile Tool.

\section{INTRODUCTION}

The companies dedicated to construction have as their main objective to deliver the projects according to the time, cost and quality agreed with the owner; however, performance on construction projects has been criticized for many years due to cost overruns and significant delays. From this, a large number of dissatisfied customers have been generated [1], one of the main reasons is the lack of use of monitoring and communication technologies, since having information in a timely manner is essential to solve problems as soon as possible and achieve the success of the projects. [2]

Zhiliang proposes a more effective and collaborative approach to building quality management process by developing a system based on the integrated application of Building Information Modeling (BIM) and indoor positioning technology. Thus achieving reducing the workload on inspectors and reducing the risk of quality management of the building. The author concludes that with these improvements, the system can save approximately $50 \%$ of the time in the entire inspection process. [3]
Likewise, Kosegoglu and Nurtan-Gunes focus on mobile BIM processes applied on the construction site in order to improve traditional project management processes through the use of tablets. The authors elaborate five processes for the case study, being those: Design management, Information management, Control and quality assurance records, Resource management and Performance management. In the result of the application it is mentioned that benefits were obtained in relation to the first three, while there were complications in optimizing both Resource Management and Performance Management. [4]

Liu, J and Shi G. base on BIM and Lean theory, this study establishes a KanBIM quality control system (QC) to achieve a more efficient process analyzing the necessary tools and technologies, thus being successful when using the proposal in complex structure projects, great construction difficulties and strict quality requirements. Finally, they achieve real-time supervision and quality control for before, during and after construction. This level of control helps to achieve high standards in Lean construction, maximize the value of a project, and control the duration, cost, and scope of a project. A KanBIM Quality Control system is built from the perspective of Quality Control, but it also has a positive role in controlling costs, duration and safety of the project, among other elements. [5]

Bravo and Mendoza base on the application of Integrated Project Delivery (IPD) and Virtual Design Construction (VDC). They obtain as a result that the main losses in the design is the dissatisfaction of the quality, the prolonged response time due to a high demand for requests which are not $100 \%$ organized and the low level of participation, which is due to the modality of contracting. By implementing these tools, they obtained savings ranging from $27.6 \%-37.4 \%$, this value is the result of quantifying the number of Request for Information (RFI) that were identified and answered on time. [6]

The study by Alizadehsalehi et al. has as its fundamental objective to explore the benefits of collaboration and communication between the contractor and the subcontractor. On the other hand, the research also focuses on showing the means that tarnish this objective through a methodology for

\footnotetext{
Digital Object Identifier (DOI):

http://dx.doi.org/10.18687/LACCEI2020.1.1.366

ISBN: 978-958-52071-4-1 ISSN: 2414-6390
}

18th LACCEI International Multi-Conference for Engineering, Education, and Technology: "Engineering, Integration, and Alliances for a Sustainable Development" "Hemispheric Cooperation for Competitiveness and Prosperity on a Knowledge-Based Economy", July 27-31, 2020, Virtual Edition. 
reviewing the literature on the subject. The author identifies breach of trust, lack of commitment by subcontractors to meet deadlines, and opportunism as factors leading to loss of collaboration. It also notes that to achieve a balance between the parties, the dependency and bargaining power of each party must be taken into account. [7]

Being the previous results focused on reducing the client's response time, in addition to use different tools and techniques to make project control efficient, this study aims to reduce the response times of subcontractors and optimize the process of the observation management using a digital transformation tool that is within the reach of small and medium-sized companies.

\section{METHODOLOGY}

To fulfill the objective of this research, building projects are evaluated, which are for residential use. Taking into account the increased participation of small and medium-sized companies, it is these that will be evaluated in the research. The sample evaluated for this study includes the projects shown in Table 1.

TABLE I

PROJECT SUMMARY

\begin{tabular}{|c|c|c|c|c|c|}
\cline { 2 - 6 } \multicolumn{1}{c|}{} & $\begin{array}{c}\text { Project } \\
1\end{array}$ & $\begin{array}{c}\text { Project } \\
2\end{array}$ & $\begin{array}{c}\text { Project } \\
3\end{array}$ & $\begin{array}{c}\text { Project } \\
4\end{array}$ & $\begin{array}{c}\text { Project } \\
5\end{array}$ \\
\hline $\begin{array}{c}\text { Num. } \\
\text { Floors }\end{array}$ & 14 & 10 & 5 & 8 & 5 \\
\hline $\begin{array}{c}\text { Num. } \\
\text { Basements }\end{array}$ & 3 & 3 & 2 & 4 & 3 \\
\hline $\begin{array}{c}\text { Num. } \\
\text { Apartments }\end{array}$ & 39 & 20 & 21 & 31 & 23 \\
\hline $\begin{array}{c}\text { Type of } \\
\text { company }\end{array}$ & Small & Medium & Small & Medium & Small \\
\hline Use & \multicolumn{5}{c|}{ Residential } \\
\hline
\end{tabular}

Projects 1, 2, and 3 are considered to delimit the problem and analyze the current process, while projects 4 and 5 were used to implement the redesigned process proposal.

The Management tools used in this research are: Pareto diagram to identify pending requests from stakeholders, it is important to take into account that pending requests are defined as activities that have not yet been attended by those responsible and that stakeholders analyzed are subcontractors, clients, home staff, neighbors, designers and supervision. Also, the flow chart to present the current and redesigned process of observation management.

The research methodology is shown in figure 1. As a first step, the information from the measurements carried out should be recorded and analyzed to determine the most critical specialty of the project which is the one with a greater number of observations, such as defects or errors existing in the items analyzed at the time of labor inspection. The stages analyzed are as follows: Architecture, Electrical Installations, Sanitary
Installations, Mechanical Installations and Structures. Likewise, the stakeholder with the highest number of requests in the "pending" status is identified.

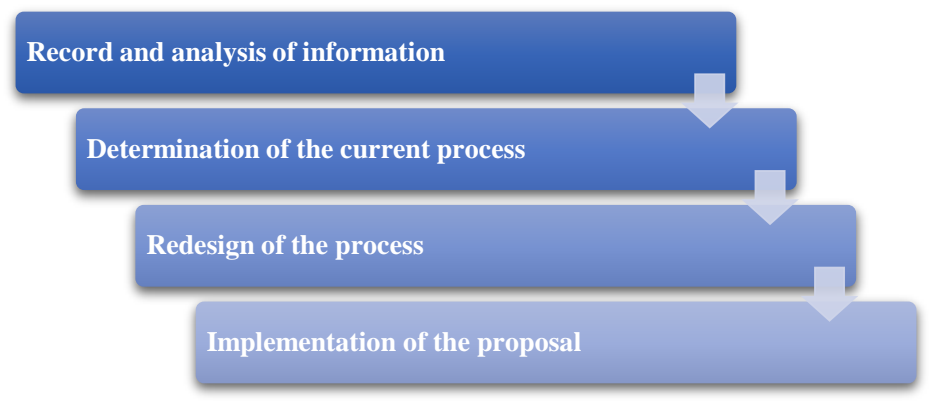

Fig. 1 Research Methodology.

Subsequently, the current process of the observation management, the managers and the time for each activity within the embodied process is determined in a flow diagram. Likewise, the average time it takes for the staff to repair the observations assigned by the quality managers is obtained.

Then, the main problems are selected through Pareto statistics and thus redesign the process including the technical and functional requirements that the technological tool must have in order to optimize the process of the observation management and reduce the response time of subcontracted personnel.

By obtaining the mobile digital tool that is most similar to the selected parameters and with the redesigned process, the proposal is implemented in projects 4 and 5 .

\section{RESULTS}

\section{A. Record and analysis of information}

The information is recorded using the number of observations recorded for a period of 30 days in projects 1,2 and 3, where the architecture specialty has $60 \%$ of the total observations in the records, as shown in figure 2 .

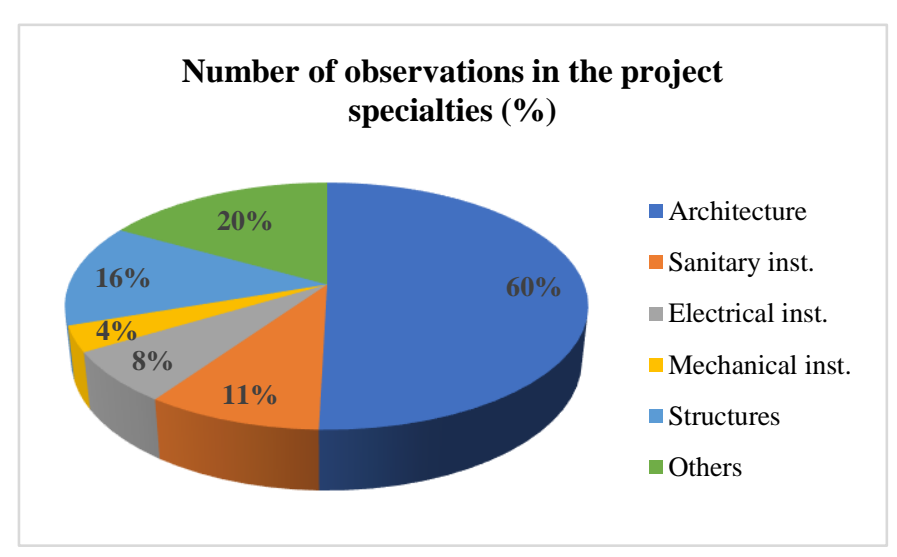

Fig. 2 Number of observations by specialty. 
From the three evaluated projects, the sub-contracted items in the Architecture specialty are: Masonry, Veneer, Doors, Paint, Window / Bulkhead and Laminate Floor, Locksmith, Marble / Granite and Furniture, the latter three being the least incidents, therefore, the evaluation will be carried out in the first six items mentioned.

Once the critical specialty has been identified, the pending requests for information are evaluated in order to identify the stakeholder with the greatest number of difficulties in observation management. See Figure 3. The following nomenclature is presented:

- S-C: Subcontractors

- SP: Supervision

- C: Client

\section{- CW: Contractor workers \\ - N: Neighbors \\ - D: Designers}

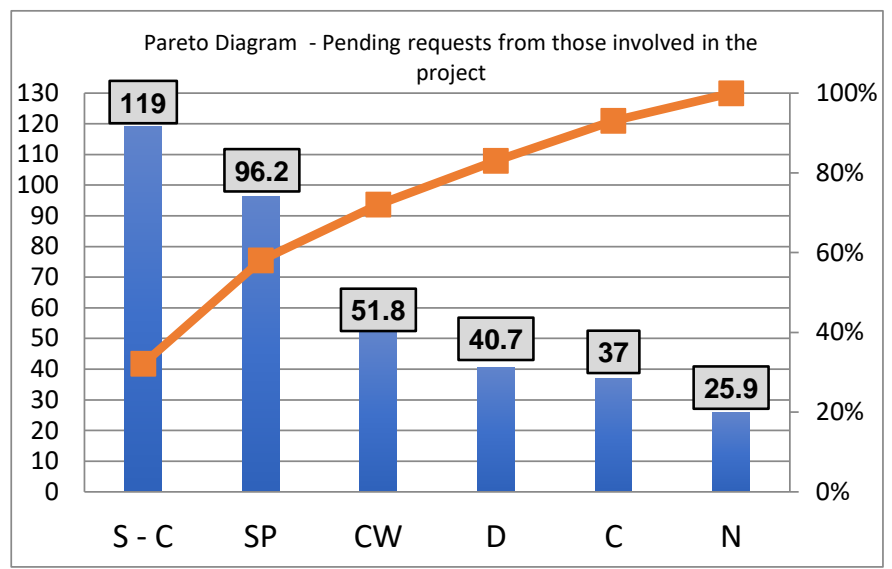

Fig. 3: Pending requests from those involved in the project.

When analyzing Figure 3 and taking into account that the information presented corresponds to the average of the information obtained in Projects 1, 2 and 3, it can be seen that there is a greater difficulty with subcontractors (119), this result indicates that for these companies it is difficult to work efficiently, and it leads to coordination with the main contractor being out of time and poorly executed.

On the other hand, the percentage of subcontractors that are in this stage is evaluated (See figure 4) and on average between projects 1, 2 and 3, 86\% of the items in this stage are subcontracted and $14 \%$ of the same is done with the house staff. This means that the coordination is much more complicated in this specialty.

\section{Distribution of the workers projects in the items of Architecture}

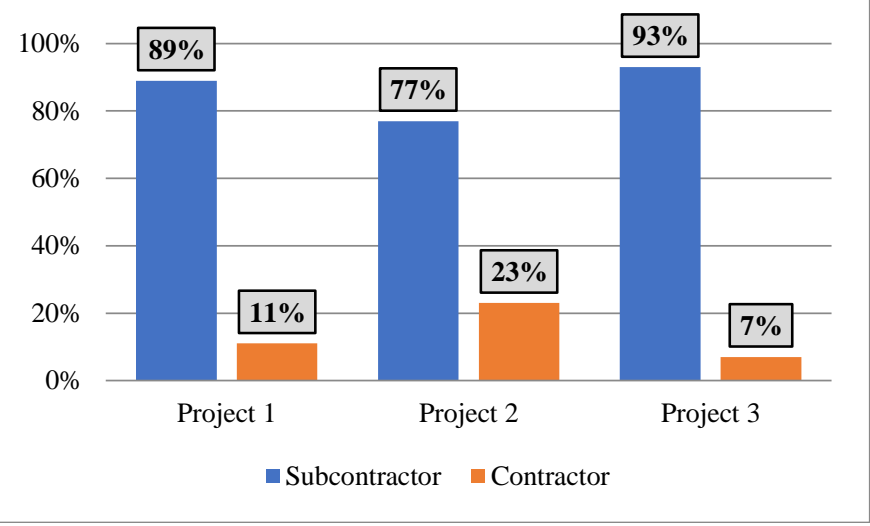

Fig. 4: Distribution of the project workers in the items of Architecture

\section{B. Determination of the current process}

Through interviews with project managers and field data records, information is obtained on the roles of the project team and the process of observation management. The work team involved is made up of the Project Manager (P.M.), the Resident Engineer (R.I.), the Production Engineer (P.I.), the Subcontractor (S/C), the Quality Engineer (Q.I.) and the Assistant of Technical Office (A.T.O.). The process starts at the request of the project manager and is carried out weekly. The flow chart of the original process is shown in figure 5, where 9 activities are identified:

- Documents printing: The plans and formats of the places where the inspection is to be carried out are printed.

- Inspection: A tour of the project is carried out where observations are recorded in a printed format and photographic evidence is taken to be included in the report.

- $\quad$ Observation transcription: All the information taken in the field is typed in an Excel format, where the photos taken are also downloaded and attached.

- Observation report: The information from the observations is consolidated and sent to those responsible via email.

- Meeting with subcontractors: The observations to be lifted are reported and the deadline to be met is indicated. It is also coordinated if they have any type of restrictions to carry out that work.

- Observation lifting: Corresponds to the activity that the subcontractor must carry out to correct the observation, it must be taken into account that a time " $\mathrm{X}$ " is placed in the flowchart because the time is highly variable depending on each activity to be carried out and it is usually measured in days rather than minutes. 
- Observation verification: A new tour is carried out verifying fulfillment with the previously delegated observations.

- Observation transcription: All the information taken in the field is typed into an Excel format, where it is detailed whether or not it complies with the lifting on the agreed date, the photos are also downloaded and attached.

- Observation report: The information of the corrected observations and those that are pending are consolidated, and sent to those responsible via email.

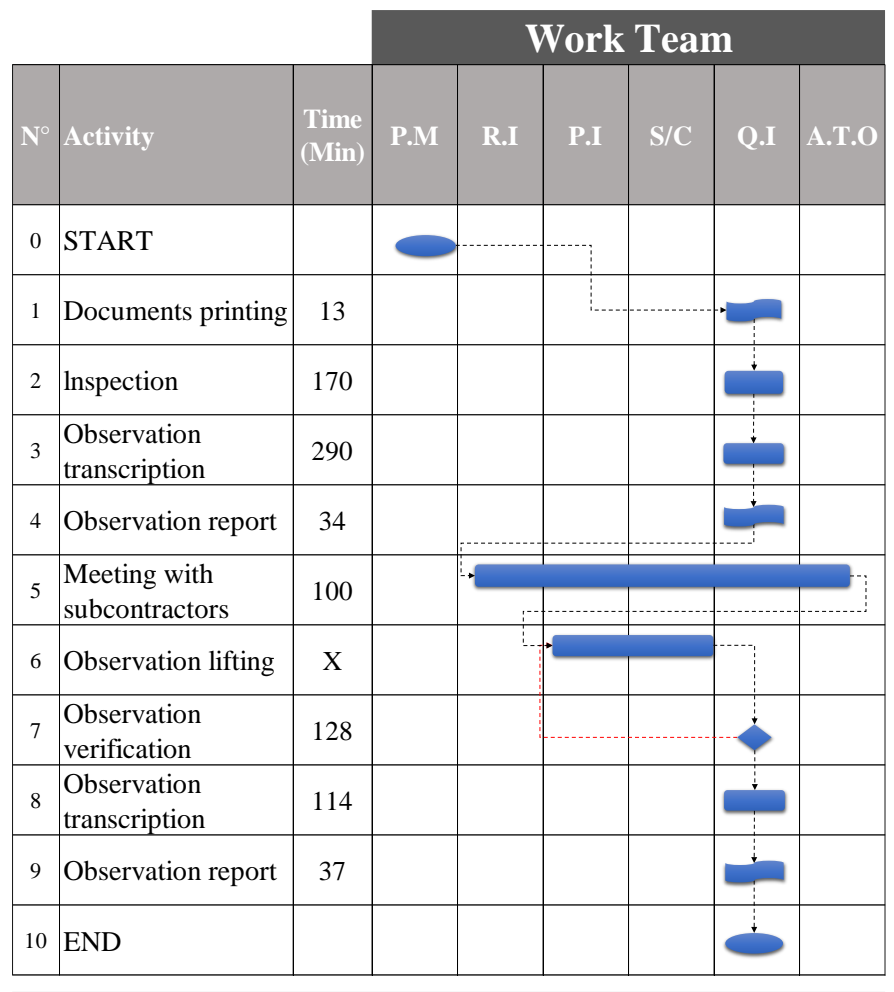

\section{TOTAL Time: 886 minutes}

Fig. 5: Flowchart of the current process of observation management.

According to the time data taken in the field for projects 1, 2 and 3 , on average, the observation management process takes a total of 886 minutes per week, of which $46 \%$ corresponds only to the observation transcription which ultimately does not correspond to a productive activity for the personnel involved.

After the meeting held with the subcontractor and taking into account the six items of the architectural specialty subcontracted with the highest incidence, the evaluation is carried out to determine " $\mathrm{X}$ " in each of the 3 projects, thus obtaining figure 6 .

Thus, an average time of 6 days is determined for the observation lifting.

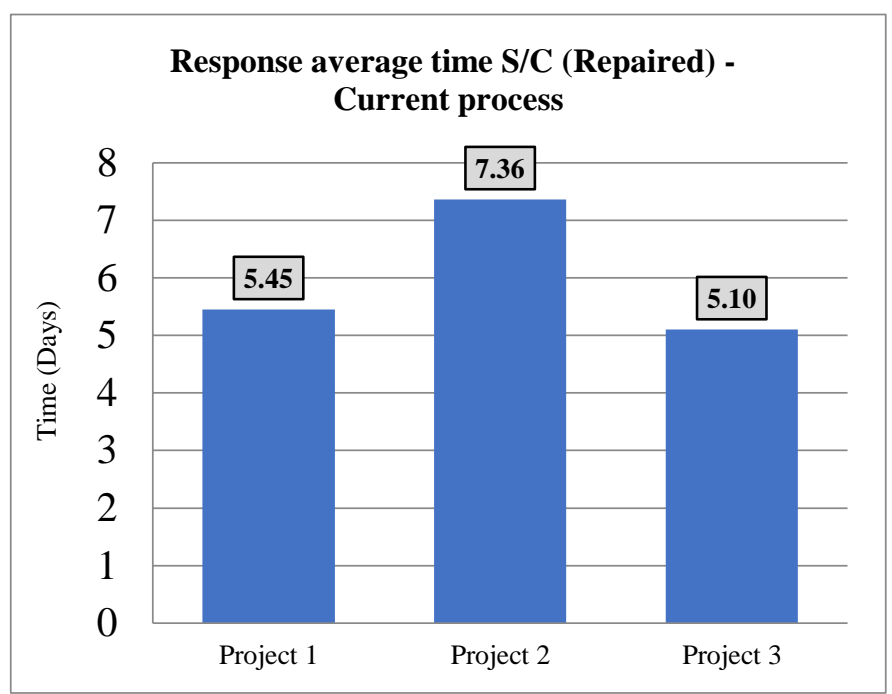

Fig. 6: Subcontractor response time - Current process.

\section{Redesign of the process}

To redesign the observation management process, it is necessary to define the characteristics and necessary requirements of the mobile digital tool so that it contributes to a more efficient process and optimizes the time of the personnel involved. See figure 7.

- Functionality
- Specific module for observation management.
- The app must contain the project plans.
- Have an open chat for the work staff.
- Must store photographic records.
- Signatures must be able to place in the application.
- Excel compatible: Must export the data to excel to control the
response time and observations.

\section{Technical considerations}

- Operating systems: It must be current on Android and IOS.

- Application size: To optimize use, it should not exceed 70 MB.

- Personalization: the app must be customizable for each work.

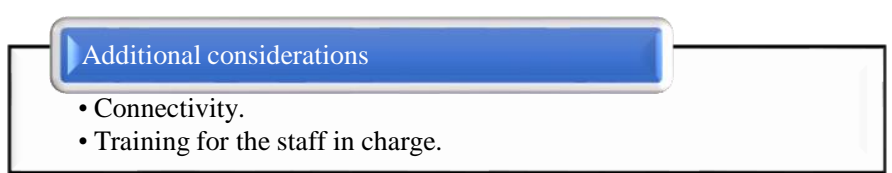

Fig.7: Characteristics and requirements of the digital tool.

With the characteristics and defined requirements and with the available alternatives digital tools in the market such as: Cloud Quality, ProPlanner, PlanGrid and Finalcad, it was decided to implement the last one because it complies with what was previously defined for the redesign of the process.

The new process includes only 4 activities and this mainly due to the incorporation of technology. By incorporating a 
digital tool, it is possible to dispense of the non-productive activities such as documents printing, observation transcription and the execution of reports that are expected to be obtained directly from the selected tool.

The redesign process is shown in figure 8:

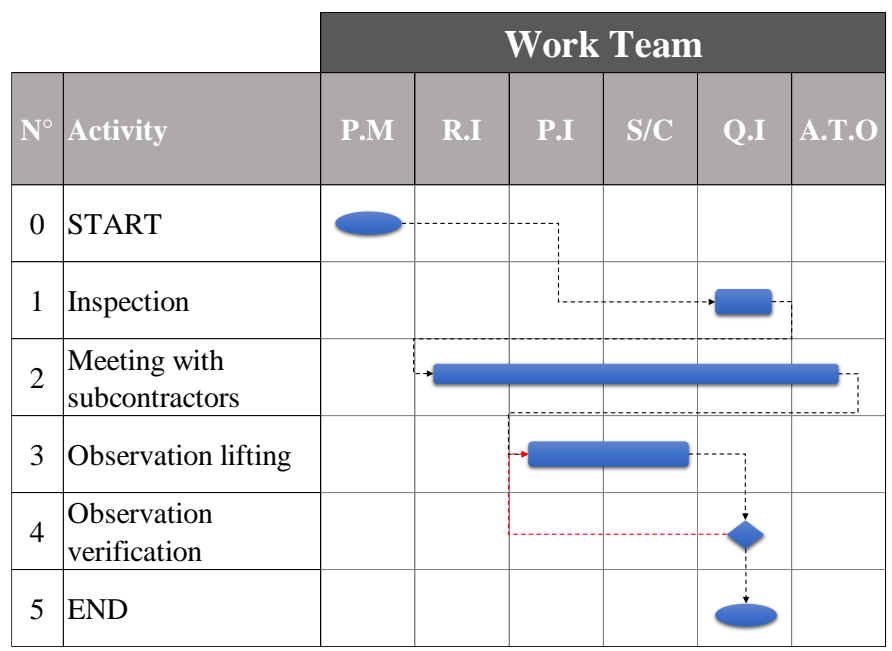

Fig. 8: Flowchart of the redesigned observation management process.

However, it is important to note that technology helps and simplifies things, but there are still activities that project staff must carry out in order to fulfill project quality standards. The activities in the new process are:

- Inspection: A tour of the project is carried out where observations are recorded in the mobile digital tool including photographic evidence and all this from a cell phone.

- Meeting with subcontractors: This activity is the same as in the current process. The observations that must be lift are reported and the deadline to be met is indicated. It is also coordinated if they have any type of restrictions to carry out that work.

- Observation lifting: This activity is the same as in the current process. Corresponds to the activity that the subcontractor must carry out to correct the observation, it must be taken into account that a time " $\mathrm{X}$ " is placed in the flowchart because the time is highly variable depending on each activity to be carried out and is generally measured in days rather than minutes.

- Observation verification: A new tour is carried out verifying compliance of the delegated observations as registered in the mobile digital tool, making it possible to incorporate photographic evidence of the state of the carried out work.

\section{Implementation of the proposal}

The proposal was applied to projects 4 and 5, where a reduction of time from 886 minutes to 498 minutes is shown as an average of the 2 projects evaluated, see figure 9 .

It is important to mention that with the new process there are activities that take longer than in the current process, such as: "Inspection" and "Observations' verification" and this because the use of the digital tool is included. In addition, the issuance of reports is verified automatically.

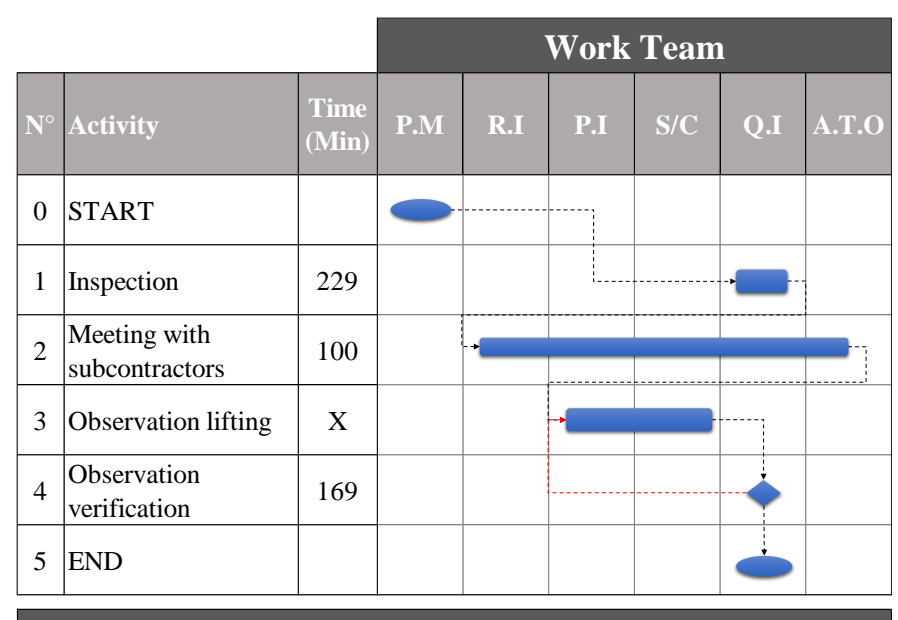

TOTAL Time: 498 minutes

Fig. 9: Flowchart of the redesigned observation management process.

Likewise, it is achieved all those involved to work more efficiently by the flow of information in real time through the mobile digital tool. Therefore, when evaluating the most incident subcontracted items in the specialty of architecture, an average of 3.5 days is obtained as the value of " $\mathrm{X}$ " in the new process. See figure 10.

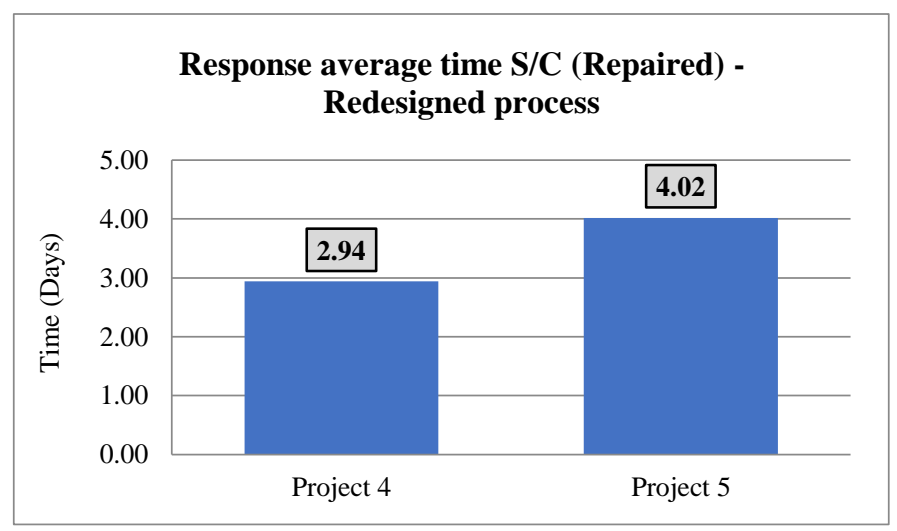

Fig. 10: Subcontractor response time - Redesigned process.

Analyzing Figure 10, it can be verified that the redesigned process reduces the response time considerably since when using the mobile digital tool, deadlines and constant warnings 
are established, also that the entire project team can have access and make constant follow-up and what is more important in real time in addition to lifting restrictions if they are reported.

\section{CONCLUSIONS}

The proposal focuses on optimizing the time and deadline involved in the observation management process, considering the incorporation of a mobile digital tool, which after its implementation manages to reduce $44 \%$ of the total time for this process, eliminating non-productive activities that develops the project team. This reduction allows the project team to get free so that they can use their time more efficiently. Likewise, when evaluating the response time of subcontractors for the observation lifting in the most incidental items of the architecture specialty, a reduction of $41 \%$ is obtained, which would mean releases and deliveries before time, so it is recommended expanding the research to assess the impact of these results on the final project delivery term.

\section{REFERENCES}

[1]. Sattineni A, Schmidt T. Implementation of Mobile Devices on Jobsites in the Construction Industry.

Procedia Eng [Internet]. 2015 [cited 2019 Jun 23];123:488-95. Available from:

www.sciencedirect.com

[2]. Behnam A, Wickramasinghe DC, Ghaffar MAA, Vu TT, Tang YH, Isa HBM. Automated progress monitoring system for linear infrastructure projects using satellite remote sensing. Autom Constr. 2016 Aug 1;68:114-27.

[3]. Ma Z, Cai S, Mao N, Yang Q, Feng J, Wang P. Construction quality management based on a collaborative system using BIM and indoor positioning. Autom Constr [Internet]. $2018 \mathrm{Aug}$ [cited 2018 Aug 28];92:35-45. Available from: https://linkinghub.elsevier.com/retrieve/pii/S09265805 1730818X

[4]. Koseoglu O, Nurtan-Gunes ET. Mobile BIM implementation and lean interaction on construction site. Eng Constr Archit Manag [Internet]. 2018 Nov 19 [cited 2019 Sep 15];25(10):1298-321. Available from: https://www.emerald.com/insight/content/doi/10.1108/ ECAM-08-2017-0188/full/html

[5]. Liu J, Shi G. Quality Control of a Complex Lean Construction Project Based on KanBIM Technology. Eurasia J Math Sci Technol Educ [Internet]. 2017 Aug 23 [cited 2018 Sep 21];13(8):5905-19. Available from: http://www.journalssystem.com/ejmste/,76615,0,2.htm 1

[6]. Bravo A, Mendoza J, Ramirez H. Application of Integrated Project Delivery and Virtual Design and Construction to reduce the impact of incompatibilities in the design stage in residential buildings. In:
Industry, Innovation, And Infrastructure for Sustainable Cities and Communities [Internet]. 2019 [cited 2020 Feb 20]. p. 24-6.

[7]. Alizadehsalehi S, Yitmen I. A Concept for Automated Construction Progress Monitoring: Technologies Adoption for Benchmarking Project Performance Control. Arab J Sci Eng. 2019 May 1;44(5):49935008. 